\section{Commentary: After the train has left the station: The utility of a late biomarker for cardiac surgery-associated acute kidney injury}

\author{
Subhasis Chatterjee, MD, ${ }^{\mathrm{a}, \mathrm{b}}$ and \\ Daniel T. Engelman, $\mathrm{MD}^{\mathrm{c}}$
}

Cardiac surgery-associated acute kidney injury (CSA-AKI) causes significant morbidity and mortality and places a considerable financial burden on health care systems. ${ }^{1}$ Its prevention has historically focused on preoperative optimization, intraoperative strategies with goal-directed perfusion, ${ }^{2}$ and early identification of kidney stress by initiating Kidney Disease Improving Global Outcomes (KDIGO) bundles. ${ }^{3}$ Renal biomarkers have been useful in facilitating earlier identification of AKI risk. ${ }^{4,5}$ Early detection of kidney stress by using biomarkers and interventions to avoid CSA-AKI is a Class IIa Enhanced Recovery After Surgery Society guideline recommendation. ${ }^{6}$

Massoth and colleagues, ${ }^{7}$ representing the multicenter International Progressive AKI Group, offer a unique contribution to CSA-AKI management. They identified a biomarker, C-C motif chemokine ligand 14 (CCL14), in a group of patients already experiencing moderate-to-severe CSA-AKI and found that elevated CCL14 predicted progression to persistent stage 3 (ie, severe) AKI and a high

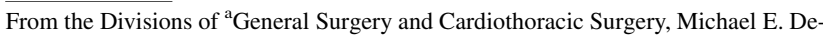
Bakey Department of Surgery, Baylor College Medicine, Houston, Tex; ${ }^{\mathrm{b}}$ the Department of Cardiovascular Surgery, Texas Heart Institute, Houston, Tex; and the ${ }^{c}$ Heart and Vascular Program, Baystate Health, University of Massachusetts Medical School-Baystate, Springfield, Mass

Disclosures: Dr Engelman consults for Edwards Lifesciences. Dr Chatterjee has served on advisory boards for Edwards Lifesciences and La Jolla Pharmaceutical Company.

The Journal policy requires editors and reviewers to disclose conflicts of interest and to decline handling or reviewing manuscripts for which they may have a conflict of interest. The editors and reviewers of this article have no conflicts of interest.

Received for publication March 18, 2021; revisions received March 18, 2021; accepted for publication March 19, 2021; available ahead of print April 2, 2021.

Address for reprints: Daniel T. Engelman, MD, Heart and Vascular Program, Baystate Health, 759 Chestnut St, Springfield, MA 01199 (E-mail: daniel.engelman@ baystatehealth.org).

J Thorac Cardiovasc Surg 2023;165:208-9

$0022-5223 / \$ 36.00$

Copyright (c) 2021 by The American Association for Thoracic Surgery

https://doi.org/10.1016/j.jtcvs.2021.03.069

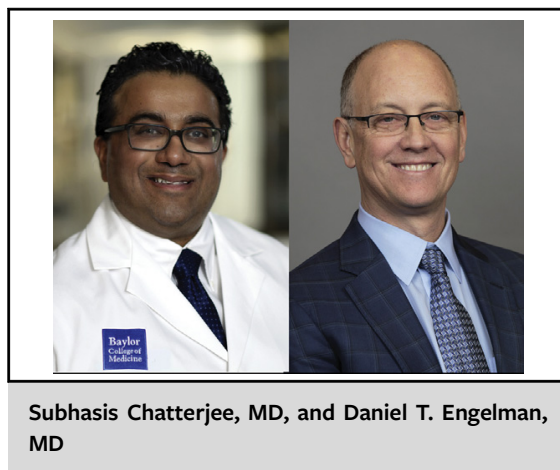

CENTRAL MESSAGE

A novel late biomarker can help identify patients with acute kidney injury that is more likely to progress in severity and to require renal replacement therapy.

likelihood that renal replacement therapy (RRT) will be required.

The CCL14 chemokine is released from tubular epithelial cells in response to injury and binds to monocytes and $\mathrm{T}$ cells, inducing chemotaxis toward the site of injury. Inflammation and fibrosis are hallmarks of the transition from AKI to chronic kidney disease and are influenced by renal monocyte/macrophage recruitment and activation. Unlike biomarkers that indicate renal stress, such as tissue inhibitor of metalloproteinases- 2 and insulin-like growth factor-binding protein $7,{ }^{8} \mathrm{CCL} 14$ is released after the kidney is already injured and an inflammatory process is well underway. As a late AKI biomarker, CCL14 recruits and activates monocytes involved in AKI progression.

This may seem to be of minor importance; after all, the AKI would have progressed to at least stage 2 by this point. However, among the most difficult issues in AKI management is knowing when to initiate RRT. The decision is more straightforward and urgent when patients have stage 3 AKI with hyperkalemia, refractory acidosis, or severe volume overload, whereas patients with azotemia and oliguria may not require RRT. In 1 study, early RRT initiation decreased 28-day mortality in patients with AKI, especially when initiated within 24 hours after cardiac surgery ${ }^{9}$ - yet, in another study, half of the patients randomized to late RRT ended up never needing RRT at all. ${ }^{10}$

Clinicians have been searching for objective data to identify patients at high risk for persistent AKI who might merit 
earlier intervention and aggressive application of an enhanced KDIGO bundle (ie, augmented cardiac output, hemoglobin, and oxygen delivery; and elimination of nephrotoxic medications). Given increasing evidence that early biomarkers can be combined with therapeutic interventions to prevent the development of AKI, the next step is investigating whether late biomarkers like CCL14 could be similarly paired with treatment strategies to prevent the progression to severe or persistent AKI and the need for RRT.

The CCL14 biomarker may also assist with risk stratification in patients with new-onset stage 2 or 3 AKI. Outcomes are influenced by the duration of renal dysfunction because patients whose kidney function resolves within 3 to 7 days have more favorable outcomes than patients with persistent AKI, who often require RRT and are at greater risk for developing chronic kidney disease. Indeed, low levels of CCL14 may help identify those patients who do not need to be placed on earlier RRT because they are less likely ever to need it.

Finally, adults with moderate or severe (KDIGO stage 2 or 3) AKI, as indicated by either elevated serum creatinine level or decreased urine output $\leq 72$ hours after surgery, were considered eligible for enrollment in the study by Massoth and colleagues. ${ }^{7}$ However, most of the patients $(79 \%)$ in that study met only the urine output criteria. This is important because surgeons frequently rely solely on creatinine level elevation to define CSA-AKI. Greater attention to oliguria, which is often associated with worse outcomes than azotemia, ${ }^{11}$ may provide earlier and more discrete identification of CSA-AKI to guide subsequent management.

The CSA-AKI train may have already left the station once a patient has stage 2 or 3 AKI. However, late biomarkers such as CCL14 may identify patients who might recover early, thereby changing patient management and improving outcomes. The analysis of this novel late biomarker by an international group of AKI experts is a major development with far-reaching ramifications for all clinicians.

\section{References}

1. Dasta JF, Kane-Gill S. Review of the literature on the costs associated with acute kidney injury. J Pharm Pract. 2019;32:292-302.

2. Magruder JT, Crawford TC, Harness HL, Grimm JC, Suarez-Pierre A, Wierschke C, et al. A pilot goal-directed perfusion initiative is associated with less acute kidney injury after cardiac surgery. J Thorac Cardiovasc Surg. 2017; 153:118-25.e1.

3. Engelman DT, Crisafi C, Germain M, Greco B, Nathanson BH, Engelman RM, et al. Using urinary biomarkers to reduce acute kidney injury following cardiac surgery. J Thorac Cardiovasc Surg. 2020;160:1235-46.e2.

4. Küllmar M, Zarbock A, Engelman DT, Chatterjee S, Wagner NM. Prevention of acute kidney injury. Crit Care Clin. 2020;36:691-704.

5. Vijayan A, Faubel S, Askenazi DJ, Cerda J, Fissell WH, Heung M, et al. Clinical use of the urine biomarker [TIMP-2] $\times$ [IGFBP7] for acute kidney injury risk assessment. Am J Kidney Dis. 2016;68:19-28.

6. Engelman DT, Ben Ali W, Williams JB, Perrault LP, Reddy VS, Arora RC, et al Guidelines for perioperative care in cardiac surgery: Enhanced Recovery After Surgery Society recommendations. JAMA Surg. 2019;154:755-66.

7. Massoth C, Küllmar M, Enders D, Kellum JA, Forni LG, Meersch M, et al. Comparison of C-C motif chemokine ligand 14 with other biomarkers for adverse kidney events after cardiac surgery. J Thorac Cardiovasc Surg. 2023;165: 199-207.e2.

8. Kashani K, Al-Khafaji A, Ardiles T, Artigas A, Bagshaw SM, Bell M, et al. Discovery and validation of cell cycle arrest biomarkers in human acute kidney injury. Crit Care. 2013;17:R25.

9. Zou H, Hong Q, Xu G. Early versus late initiation of renal replacement therapy impacts mortality in patients with acute kidney injury post cardiac surgery: a meta-analysis. Crit Care. 2017;21:150.

10. Gaudry S, Hajage D, Schortgen F, Martin-Lefevre L, Pons B, Boulet E, et al Initiation strategies for renal-replacement therapy in the intensive care unit. $N$ Engl J Med. 2016;375:122-33.

11. Kellum JA, Sileanu FE, Murugan R, Lucko N, Shaw AD, Clermont G. Classifying AKI by urine output versus serum creatinine level. J Am Soc Nephrol. 2015;26:2231-8 